\title{
The Problem of Ethical Vagueness for Expressivism
}

\author{
Nicholas Baima
}

Accepted: 15 January 2014 / Published online: 14 February 2014

(C) Springer Science+Business Media Dordrecht 2014

\begin{abstract}
Ethical vagueness has garnered little attention. This is rather surprising since many philosophers have remarked that the science of ethics lacks the precision that other fields of inquiry have. Of the few philosophers who have discussed ethical vagueness the majority have focused on the implications of vagueness for moral realism. Because the relevance of ethical vagueness for other metaethical positions has been underexplored, my aim in this paper is to investigate the ramifications of ethical vagueness for expressivism. Ultimately, I shall argue that expressivism does not have the resources to adequately account for ethical vagueness, while cognitivism does. This demonstrates an advantage that cognitivism holds over expressivism.
\end{abstract}

Keywords Ethics $\cdot$ Meta-ethics $\cdot$ Vagueness $\cdot$ Expressivism $\cdot$ Non-cognitivism $\cdot$ Uncertainty

Ethical vagueness has garnered little attention. This is rather surprising since many philosophers have remarked that the science of ethics lacks the precision that other fields of inquiry have. ${ }^{1}$ Of the few philosophers who have discussed ethical vagueness the majority have focused on the implications of vagueness for moral realism. ${ }^{2}$ Because the relevance of ethical vagueness for other metaethical positions has been underexplored, my aim in this paper is to investigate the ramifications of ethical vagueness for expressivism. ${ }^{3}$ Ultimately, I shall argue that expressivism does not have the resources to adequately account for ethical vagueness, while cognitivism does. This demonstrates an advantage that cognitivism holds over expressivism.

\section{Expressivism}

Before I offer my argument showing that ethical vagueness raises problems for expressivism, it will be helpful to briefly review the central tenets of expressivism, and to provide a basic

\footnotetext{
${ }^{1}$ See especially Aristotle (2002) 1094b, 12-18.

${ }^{2}$ See Constantinescu (Forthcoming); Schiffer (2003); Shafer-Landau (1995); (1994).

${ }^{3}$ I will solely focus on full non-cognitivist versions of expressivism and will not discuss hybrid theories.

N. Baima $(\bowtie)$

The Department of Philosophy, Washington University in St. Louis, One Brookings Drive, St. Louis, MO 63130-4899, USA

e-mail: NichBaima@gmail.com
} 
overview of the phenomenon of ethical vagueness. Expressivists maintain that there is a sharp distinction between descriptive claims and normative judgments. On one hand, descriptive claims express factual beliefs about the world; in contrast, normative (e.g. moral, epistemic, practical) judgments express a distinctive non-cognitive mental state with a conative structure. This difference can be explained in terms of the 'direction of fit'. Cognitivists maintain that normative judgments attempt to represent or fit the world. For example, to hold that 'murder is wrong' is to believe that the world is such a way that it is wrong to murder. In contrast, noncognitivists hold that normative judgments attempt to direct action and change the world such that the world fits one's normative judgments. For example, to judge that 'murder is wrong' is to take a specific attitude towards murder. This attitude expresses the norms concerning murder which one has adopted or hopes to adopt. This feature of expressivism is purported to offer two advantages over other metaethical theories. It clearly demonstrates why normative judgments are motivational - they are conative states rather than belief states. Additionally, since there are no (robust) moral properties, expressivism accords with metaphysical naturalism in a simple way.

Expressivism advances upon its predecessor emotivism in two main ways. ${ }^{4}$ First, expressivists hold that the current emotional state an agent is in can come apart from the norms she is expressing when she makes a normative judgment. Justin D'Arms and Daniel Jacobson refer to this as the 'response dependency thesis' (RDT hereafter). ${ }^{5}$ A non-cognitive formulation of RDT is as follows:

RDT To judge that $X$ has some evaluative property $P$ is to approve of feeling $F$ in response to $X$.

For instance, when an agent says that 'murder is wrong', she might be expressing that it is appropriate to feel anger in response to murder, while not being angry herself. This is not possible under emotivism. Emotivists maintain that when one makes a moral judgment one is simply expressing the emotional state one is in. For example, to judge that 'murder is wrong' just is to feel an emotion - say anger - in response to thinking about murder.

Second, expressivists adopt a deflationary account of truth where truth is understood in terms of the appropriateness of an agent's expressed attitude towards a situation. ${ }^{6}$ The main idea is that particular attitudes are fitting for specific situations while other attitudes are unfitting for these situations. Additionally, the normative judgments that an agent makes must be consistent with an agent's normative commitments. ${ }^{7}$ This advances upon emotivism which simply maintains that normative judgments are not truth-apt.

\section{The Problem of Ethical Vagueness}

Let us turn our focus to ethical vagueness. An expression is vague if it has borderline cases that cannot be resolved with any amount of disambiguation of terms or empirically discoverable

\footnotetext{
${ }^{4}$ See Ayer (1936); Hare (1952); Stevenson (1944). For a discussion concerning emotivism and ethical vagueness see Sorensen (1990).

5 D'Arms and Jacobson (2000) maintain that all neo-sentimentalists adopt RDT, including both cognitivist and non-cognitivist. See McDowell (1997a); (1997b); Wiggins (1997); Blackburn (1998); (1993); Gibbard (2003); (1990).

${ }^{6}$ See Gibbard (2003); (1990); Blackburn (1998); (1993). For a new discussion of expressivism and truth see Schroeder (2010).

${ }^{7}$ Different theorists account for these features in different ways, but the particular variations are not relevant for the purposes of this paper. What is relevant is that expressivists attempt to provide a normative framework that can mesh with logical systems to overcome the otherwise devastating Frege-Geach problem. For discussions of the Frege-Geach problem see Unwin (1990); Shroeder (2008); Dreier (2006).
} 
information. For example, it is incorrect to apply the predicate 'tall' to a five foot man, while it is correct to apply the predicate 'tall' to a seven foot man. Nonetheless, it is unclear if it is correct to apply the predicate 'tall' to a six foot man. That is to say, that a six foot man is a borderline case of a tall man.

The classic way of demonstrating that a predicate is vague is to apply it in a sorites argument. If a predicate can be shown to be soritical, then its application admits of enough tolerance to generate borderline cases. Consider this example:

P1) One grain of sand does not make a heap.

P2) If one grain of sand does not make a heap, then two grains of sand does not make a heap.

P3) If two grains of sand does not make a heap, then three grains of sand does not make a heap.

C) 100 million grains of sand does not make a heap.

Each premise seems true because the difference of one grain of sand seems too small to affect the application of the predicate. This demonstrates that the predicate 'heap' is tolerant. In between (P1) and the absurd conclusion will be borderline cases of 'heap'. From this we can conclude that the predicate 'heap' is vague. This can be illustrated as follows:

10 grains of sand or less / ? / 100 million or more

clearly not a heap

borderline

clearly a heap

A similar example can be used for ethical predicates like 'right', 'wrong', 'good', 'bad', 'permissible', and 'impermissible'. Imagine there is a community jar with 5,000 pennies in it. It is not wrong (i.e. permissible) to take a few pennies from the jar when one needs some change. From this simple convention, we can generate the following sorites:

P1) Taking one penny is not wrong.

P2) If taking one penny is not wrong, then taking two pennies is not wrong.

P3) If taking two pennies is not wrong, then taking three pennies is not wrong.

C) Taking 5,000 pennies is not wrong.

This demonstrates that the ethical predicate "wrong" is vague. This can be illustrated as follows:

2 pennies or less / ? $\quad / \quad 3,000$ or more

clearly not wrong $\quad$ borderline clearly wrong

This highlights that it is clearly not wrong (i.e. permissible) to take a couple of pennies from the jar, but it is clearly wrong (i.e. forbidden) to take anything close to the whole jar. However, in the middle it is vague as to whether taking $V$ pennies is wrong, where $V$ represents an 
amount of pennies that is a borderline case of wrong to take. This demonstrates that ethical predicates such as 'wrong' can be vague.

This raises a problem for expressivists. Suppose that Tom is watching Jessica take pennies from the jar. On the first day, Jessica innocently takes one penny. The next day Jessica takes $V$ pennies. And on the final day, feeling avaricious, Jessica takes 3,000 pennies. It seems clear that Tom would make the following judgments about day one and day three, but because day two involves ethical vagueness it is unclear what Tom would judge. This can be represented as follows:

A) Cognitive Framework

1) Tom believes that it is not wrong for Jessica to take one penny.

2) Tom believes that it is (?) to take $V$ pennies.

3) Tom believes that it is wrong for Jessica to take 3,000 pennies.

The question mark in (2) denotes that Tom is in a state of puzzlement and does not know what to believe. By utilizing one of the many popular theories of vagueness cognitivists can account for Tom's puzzlement. For example, if they take the epistemicist route, they could argue that there is a truth of the matter as to whether it is wrong to take $V$ amount of pennies, however the truth is empirically unknowable. ${ }^{8}$ Or perhaps they might adopt another theory of vagueness such as supervaluationism or onticism where the vagueness is explained in terms of a kind of indeterminacy. ${ }^{9}$ Indeterminacy can be accounted for by deviating from classical logic such as by denying bi-valance. I am not going to defend one of these views, my point is simply that the cognitivist has many ways to account for vagueness and to explain Tom's judgment in (2).

We can transform Tom's moral judgments into a non-cognitive framework by utilizing a non-cognitive version of RDT. Recall that RDT is:

RDT To judge that $X$ has some evaluative property $P$ is to approve of feeling $F$ in response to $X$.

Because the pennies example focuses on the moral quality of wrongness, let us make $F$ the moral emotion of anger. With this in mind we can reformulate Tom's judgments as follows:

B) Non-Cognitive Framework

$\left.1^{*}\right)$ Tom approves of not being angry in response to someone taking one penny.

$\left.2^{*}\right)$ Tom (?) in response to someone taking $V$ pennies.

$3^{*}$ ) Tom approves of being angry in response to someone taking 3,000 pennies.

The question this paper raises is: can expressivists adequately account for Tom's moral judgment in $\left(2^{*}\right)$ ? Or to put the problem more generally: can expressivists provide a viable attitude that expresses the normative judgments we make when we confront the phenomenon of ethical vagueness? I will argue that they cannot. In the next section I argue that expressivists do not have the resources to account for either uncertainty or indeterminacy. Thus, expressivists cannot mimic the answers cognitivists give to (2). This marks a clear advantage cognitivists have over expressivists.

\footnotetext{
${ }^{8}$ See Williamson (1994); Sorensen (1988).

${ }^{9}$ See Lewis (1982); Fine (1975); Tye (1989); Rosen and Smith (2004); Hyde (2008); Schiffer (2010).
} 


\section{Mirroring Strategies}

As I previously explained, cognitivists can explain Tom's mental state in (2) as puzzlement. Cognitivists can account for this puzzlement in terms of either (a) uncertainty or (b) indeterminacy. In this section I will argue that non-cognitivism cannot plausibly account for either uncertainty or indeterminacy.

Let us first turn our attention to uncertainty. Strictly speaking, uncertainty is a cognitive notion, which is usually explained in terms of degrees of belief. The degree of belief increases the more confident one is that a proposition is true and decrease the less confident one is that a proposition is true. For example, one could capture Tom's puzzlement in (2) by asserting that Tom believes to degree $D$ that taking $V$ pennies is wrong, where $D$ is a number that reflects very little confidence that the action is wrong. ${ }^{10}$ Because expressivists are committed to noncognitivism they must explain degrees of belief in terms of degrees of some conative state, such as approval. ${ }^{11}$ For instance, the non-cognitivist might maintain that Tom approves to degree $D$ of being angry at Jessica taking $V$ pennies, where $D$ is a number that reflects that Tom weakly approves of being angry at Jessica taking $V$ pennies.

However, to say that Tom weakly approves of being angry at Jessica taking $V$ pennies is ambiguous between two distinct judgments. ${ }^{12}$ It can either represent Tom's judgment that he has little confidence that anger is an appropriate response to someone taking $V$ pennies. Or, it can represent Tom's judgment that taking $V$ pennies is not a morally significant issue. The former judgment reflects how confident Tom is that things are as he judges them to be, call this 'certitude'. The latter judgment reflects Tom's attitude towards the moral significance of this action, call this 'importance'. ${ }^{13}$ Of course, expressivists can accommodate this worry by designating that the degree of approval represents certitude. However, if they do this, then they will have to develop a means of explaining importance.

Expressivists might respond by arguing that they can represent importance in terms of a firstorder approval and can represent certitude in terms of a second-order approval. ${ }^{14}$ For example, when I judge that anger is appropriate in response to murder, I approve of approving of anger in response to murder. The degree of the first-order approval can be adjusted in terms of how bad I judge this action. The second-order approval can be gradable in terms of how certain I am. For example, if I really approve of approving anger in response to murder, then I have a high-degree of certitude that anger is the correct response. But if I only slightly approve of approving anger in response to murder, then I have a low-degree of certitude that anger is the correct response.

This response faces two serious problems. ${ }^{15}$ The first problem is that this account is riddled with arbitrariness. There does not seem to be a substantive reason to make the first-order approval correspond to importance and the second-order approval correspond to certitude. The

\footnotetext{
${ }^{10}$ Note that some philosophers maintain that the kind of uncertainty we face when we encounter the phenomenon of vagueness is unique and it cannot be captured in terms of standard degrees of belief. See Schiffer (2003); Wright (2001).

${ }^{11}$ It is an interesting question as to just how fine grained conative states can be. If they are not as fine-grained as degrees of belief, then this would be a serious problem for expressivists. Krister Bykvist and Jonas Olson raise a similar concern (2009).

${ }^{12}$ Michael Smith first introduced this problem (2002). Feeling the force of this problem some expressivists have opted to adopt hybrid accounts in which there are cognitive and non-cognitive features in normative judgments. I will not discuss these views in this paper since I am primarily concerned with purely non-cognitive versions of expressivism. For hybrid views see Lenman (2003); Ridge (2007). For criticisms of these views see Bykvist and Olson (2009).

13 These are Smith's terms (2002).

${ }^{14}$ See Smith (2002), pg. 317-318.

${ }^{15}$ See Smith (2002), pg. 317-318.
} 
second problem is that certitude can come apart from a second-order approval. On this model the more strongly an agent approves of her approval the higher degree of certitude she has. However, it is conceivable that an agent can strongly approve of her approval without being certain. To see this, consider a modified version of Krister Bykvist and Jonas Olson's Kantian demon. $^{16}$

Suppose a Kantian demon threatens to kill your dog if you do not approve of always keeping promises. The demon does not care about whether you actually keep your promises; he only cares about whether you approve of always keeping your promises. Because you care about your dog deeply you have a strong reason to approve of always keeping your promises. Likewise, since you think this approval is justified, you have a reason to approve of this approval. Nevertheless, the Kantian demon has not supplied you with a reason to always keep your promises-you might be uncertain if you have a reason to always keep them. This is devastating for this model because on it strongly approving of the approval that one always keeps a promise means that one is confident that it is important to keep one's promises, which ostensibly provides one with a reason to keep a promise.

Notice that cognitivists do not fall prey to this evil demon. For example, if you believe that people should always keep their promises, then you take yourself to have a reason to keep your promises - namely that you think it is wrong if you do not. However, as the evil demon case demonstrates, you might have a reason to approve of always keeping promises without believing that you should always keep your promises.

Another strategy is to represent certitude through the degree of approval and to represent importance through the intensity of the emotion that one is approving of.$^{17}$ The more confident one is that an action is wrong, the more one will approve of being angry in response to this action. The more morally significant the action is the more intense the anger one will approve of. For instance, suppose Tom is very confident that it is only moderately bad to take 3,000 pennies. This can be expressed as him strongly approving of feeling a small degree of anger in response to someone taking 3,000 pennies.

Nevertheless, the Kantian demon strikes again. Suppose that a Kantian demon will kill your dog if you do not always approve of being angry when one breaks a promise. The demon does not care if you do not actually keep your promises. Nor does the demon care if you are actually angry in response to one breaking a promise. The demon only cares if you approve of being angry when promises are broken. The demon has given you a strong reason to approve of being angry when one breaks a promise, but you lack certainty whether one has a reason to keep one's promise. This is problematic for this model because according to it strongly approving of being angry in response to an action means that one is confident that the action is wrong, which should supply a reason not to do the action.

These Kantian demon worries demonstrate that expressivists cannot account for both certitude and importance, and thus cannot provide a viable attitude that expresses uncertainty. Expressivists might respond to these evil demon concerns by adding more structure to their theory. It is likely that this additional structure will more closely mirror the role belief plays for cognitivism. This might allow them to capture uncertainty, which strictly speaking is a cognitive term. Nevertheless, this leads to an additional problem. The more expressivism becomes like cognitivism, the less of an advantage expressivism will have in accounting for motivation. ${ }^{18}$ The seriousness of this worry cannot be stressed enough. After all, one of the

\footnotetext{
${ }^{16}$ Bykvist and Olson (2009), pg. 206.

${ }^{17}$ Andrew Sepielli discusses a similar maneuver (2012).

${ }^{18}$ Sepielli raises this worry (2012), pg. 199-200.
} 
presumed advantages of expressivism is that it (alone) can provide a plausible explanation for how normative judgments are closely linked to motivation.

As I previously discussed another way to account for Tom's puzzlement in (2) is through indeterminacy. For the purposes of this paper, to judge that the ethical worth of action $A$ in situation $S$ is indeterminate is to maintain that $A$ in $S$ is neither determinately wrong nor determinately right. Notice how this differs from uncertainty. Under uncertainty one is not committed to a particular judgment about the ethical worth of $A$ in $S .{ }^{19}$ However, if one judges that the ethical value of $A$ in $S$ is indeterminate, one is making a claim about the ethical quality of the action - that it is neither determinately wrong nor determinately right. ${ }^{20}$ There are at least three broad ways which philosophers have accounted for indeterminacy: ontologically, linguistically, and psychologically. I will discuss each of these views and argue that they are not available to the expressivist.

Onticists argue that vagueness arises because there are vague properties in the world. ${ }^{21}$ That is, the source of indeterminacy is ontic. This is an unattractive option for expressivists since they are committed to there not being any (robust) moral properties. Provided that expressivists are not comfortable with moral properties they will likely want to avoid talk of vague moral properties.

Supervaluationists maintain that the source of vagueness is semantic. ${ }^{22}$ Perhaps the clearest way of explaining supervaluationism is to contrast it with onticism. Onticists maintain that the term 'tall' picks out a single property and the property is rough around the edges, and this ontological roughness is the cause of vagueness. On the other hand, supervaluationists maintain that concepts are sharp, but that terms pick out a whole range of related concepts. For example, the term 'tall' can mean a 6'5" person, a 6'4" person, a 6'3" person... and so on. Vagueness arises because our linguistic community is semantically undecided about which concepts are precisely denoted by a specific term. Propositions about concepts that we are semantically undecided about lack a truth value. For example, the proposition that it is wrong to take $V$ pennies is neither true nor false.

In many ways, supervaluationism seems like a fitting candidate for expressivism. After all, supervaluationists hold that vagueness is a semantic issue, while expressivists maintain that normativity is grounded in a linguistic practice. For example, Gibbard argues that the norms we accept develop through a process of normative discourse, where individuals discuss what is appropriate to think and to feel about certain situations. ${ }^{23}$ Perhaps expressivists might argue that ethical vagueness is a result of imprecise normative discourse. For example, during normative discourse individuals might come to a consensus on many normative issues. But because it is not possible to discuss every moral situation, we are left with ethical vagueness. This is a plausible causal story of ethical vagueness, but can expressivists represent this indeterminacy?

As I discussed above supervaluationists maintain that the proposition that it is wrong to take $V$ pennies is neither true nor false. However, because expressivists maintain that normative assertions are non-propositional we have to develop a fitting non-cognitive analogue to this proposition. By utilizing a non-cognitive version of RDT we get the following corresponding

\footnotetext{
${ }^{19}$ Indeterminacy is also distinct from underdetermination, but this distinction is not relevant for the purposes of this paper.

${ }^{20}$ Indeterminacy has played a number of explanatory roles in ethics. It has been used to explain the general phenomenon of vagueness. See Shafer-Launau (1995); Railton (1992). Additionally, some moral realists have argued that indeterminacy provides an explanation for the seemingly intractable nature of ethical disagreement. Shafer-Landau (1994). pg. 336.

${ }^{21}$ See Rosen and Smith (2004); Hyde (2008); Schiffer (2010).

${ }^{22}$ For discussions of supervaluationism see Lewis (1982); Fine (1975); Tye (1989).

${ }^{23}$ Gibbard (1990), pg. 72.
} 
non-cognitive attitude: Tom neither approves nor disapproves of anger in response to taking $V$ pennies. Hence, the judgment that it is neither appropriate nor inappropriate to feel anger entails $\neg(P$ or $\neg P)$. The problem is that this state is logically equivalent to the inconsistent conjunction $(P \& \neg P) .{ }^{24}$ The problem with denying the principle of non-contradiction is that the most plausible solutions to the Frege-Geach problem operate under the framework that $P$ and not $P$ are inconsistent. Mark Schroeder calls this 'inconsistency transmission', and he argues that it is essential for any solution to the Frege-Geach problem. He writes, 'Whatever story you defend on this count, it must turn out that necessarily, if $P$ has this property, then $\neg P$ does not have it. (Or that if you bear this relation to $P$, then you don't bear it to $\neg P$ )'. ${ }^{25}$

Interestingly enough, Schroeder's 'being for expressivism' has a way of avoiding this sort of problem. On Schroeder's 'bifurcated semantics' if one is for $P$, then it follows that one is for $(\neg P)$. Likewise if one is for $\neg P$, then it follows that one is not for $(\neg \neg P)$. However, Schroeder has a third kind of state which he calls 'disacceptance' or 'rejection'. ${ }^{26}$ Rejecting $P$ is inconsistent with being for $P$, but is weaker than being for $\neg P{ }^{27}$ Schroeder uses a modified version of Kleene's three valued logic to represent the three kinds of states. ${ }^{28}$

Schroeder argues that one benefit of having a theory of expressivism that has 'rejection' is that it provides an explanation for the 'liar paradox'. ${ }^{29}$ Consider a sentence that says of itself that it is not true. On the one hand, you do not believe the 'liar', but on the other hand you do not believe its negation. Nevertheless, it is not the case that you are undecided, 'you've worked out what your position is going to be, and it is to disbelieve both the strengthened liar and its negation. What you are for, I say is not proceeding as if $P$, and you are also for not proceeding as if $\neg P^{\prime} .{ }^{30}$ In other words, you are committed to rejecting the statement.

Why cannot expressivists maintain that one is in a state of rejection or disacceptance when one confronts ethical vagueness? In response to this I would first like to point out that Schroeder maintains that disacceptance ends up conflating with approving the negation, he calls this the 'new new negation problem. ${ }^{31}$ However, because this objection is idiosyncratic to Schroeder's 'bifurcated semantics', I will not focus on this critique.

As I see it, the biggest problem with using rejection to explain the phenomenon of ethical vagueness is that doing so conflates two distinct phenomenological states. Phenomenologically the structure of the liar paradox is very different from vagueness. In the liar paradox one feels the inconsistency immediately. Neither answer to the liar seems all that appealing. Hence the reason that something like rejection might actually be a proper solution to the paradox. By rejecting or disaccepting the liar, one is committed to the liar being incoherent. Nevertheless, this is not the case with vagueness. When Tom watches Jessica take $V$ pennies, it is not the case that Tom thinks that it is incoherent to say that she did something wrong or that she did something right. Rather, it is just the opposite. The problem that vagueness raises is that it seems to leave us with two equally compelling answers. Therefore, if expressivists use the state of rejection as a means for explaining ethical vagueness, then they will be confusing incoherence or underdetermination with overdetermination. In other words, this would result in the conflation of two different kinds of mental states.

\footnotetext{
${ }^{24}$ For a related discussion on vagueness and moral dilemmas see Sorensen (1991).

${ }^{25}$ Schroeder (2008), pg. 167.

${ }^{26}$ In Schroeder (2008) this state is called 'disacceptance', but in Schroeder (2010) something similar to this state is called to as 'rejection'.

${ }^{27}$ Schroeder (2008), pg. 102-103.

${ }^{28}$ Schroeder (2008), pg. 108-113.

${ }^{29}$ See Schroeder (2008), pg. 102; (2010).

${ }^{30}$ Schroeder (2008), pg. 102.

${ }^{31}$ Schroeder (2008), pg. 113-115.
} 
Hence, the expressivist needs another way of accounting for semantic indeterminacy. I will consider three other ways the expressivist might represent this. First, she might maintain that when one confronts ethical vagueness one approves of having no sentiment in response to this action. On this model, approving of having no sentiment corresponds to maintaining that a proposition lacks a truth value. The problem is that this solution is in tension with RDT. Under RDT there is a necessary connection between moral judgments and attitudes - to make a moral judgment about $X$ just is to express that it is appropriate to feel a particular emotion $F$ in response to $X$. Thus, this solution is actually a counterexample to RDT, since it suggests that there is a moral judgment without an accompanying sentiment. Because this answer violates one of the core components of expressivism, this response is not available to expressivists.

A second and slightly modified version of the previous response is that when confronted with ethical vagueness one approves of refraining from making a moral judgment. On this model approving of not making a moral judgment corresponds to asserting that a proposition lacks a truth value. However, this answer seems to reduce to uncertainty. Consider the following distinction: there are at least two possible reasons why one refrains from making a moral judgment about a particular subject matter. The first is because the agent never considers the subject matter. For example, I refrain from making moral judgments about the War of Jenkins' Ear because I never think about this obscure war. The second is that an agent considers the subject matter but is unable to come to a conclusion about the moral standing of the subject matter. For example, Sarah considers the War of Jenkins' Ear but is unable to come to a conclusion about the moral permissibility of the war. Because of this she refrains from making a moral judgment about the war. The situation involving ethical vagueness is akin to the latter example. Tom is actively watching Jessica take pennies and is critically reflecting upon this. The important question is why are both Sarah and Tom unable to come to a conclusion about the subject they are considering. The most plausible answer is that they are uncertain. Therefore, if expressivists want to argue that the appropriate response to ethical vagueness is to avoid making a normative judgment, then they need to show how uncertainty can feasibly be explained in a non-cognitive framework and I have already explained why this is a steep challenge.

Additionally, even if we assume for the sake of argument that abstaining from making a normative judgment is not intimately tied to normative uncertainty, this answer is still problematic. After all, if cognitivism allows for normative judgments about ethical vagueness and expressivism does not, then this is an advantage for cognitivism, especially if Mark Sainsbury is right that 'the throbbing centers of our lives appear to be describable only in vague terms' ${ }^{32}$ In other words, this demonstrates how cognitivism allows for a richer normative vocabulary, which in turn allows for more fine grained evaluations of the practice of ethics.

A third way an expressivist could attempt to capture indeterminacy might be to maintain that indifference is an appropriate attitude to take towards ethical vagueness. On this model approving of indifference corresponds to asserting that a proposition is neither true nor false. Indifference involves not having a preference between options, such that you do not care which of the options obtains. For trivial and artificial examples, such as the pennies example, the 'indifference attitude' might be a plausible solution because the outcomes of the examples seem unimportant. However, there are many examples involving ethical vagueness in which one cares a great deal about the moral worth of the action, such as issues involving euthanasia, abortion, autonomy, resource allocation, praise, and blame.

Consider the following example involving abortion. ${ }^{33}$ One criterion which some argue is morally relevant to maternal obligation is whether the mother is responsible for creating the

\footnotetext{
32 Sainsbury (1997), pg. 251.

33 Shafer-Landau uses a similar example for different purposes (1995), pg. 88.
} 
situation of fetal dependence. A clear case of bearing responsibility is if a woman had intercourse with the intention of conceiving, while a clear case of not bearing responsibility would be a victim of rape. However, the situation becomes fuzzy when contraception is introduced. Perhaps a woman is responsible if the contraceptive method she uses is one percent effective, and perhaps not if the method is ninety-five percent effective. But what if the contraceptive method is fifty percent effective? In no way is this meant to be a substantive point about the permissibility of abortion. Rather the intent is to illustrate how ethical vagueness can apply to morally significant issues, which individuals might not be indifferent to. Hence, indifference is not always an appropriate attitude to adopt when faced with ethical vagueness. Therefore, although supervaluationism seems like a natural way for expressivists to account for vagueness, they do not have the resources to apply it.

The third type of indeterminacy I will explore is psychological in nature. Stephen Schiffer has argued that when we confront the phenomenon of vagueness we are left in a quandary, however our state of puzzlement does not reduce to standard accounts of uncertainty. ${ }^{34}$ As I previously stated uncertainty is explained in terms of degree of belief. This degree of belief represents how confident I am that a proposition is true. A low degree of belief represents ignorance, which could improve with an epistemically superior vantage point. For instance, suppose I am awaiting a friend, Felipe, to visit my house. Typically, I do not have many unannounced visitors. Thus, when I hear a knock on my door I am fairly confident that Felipe is at the door. However, if I heard Felipe's voice or saw him through the peep hole, then my degree of belief that Felipe is at my door would increase. Schiffer argues that the same is not true when we face vagueness. When I am trying to determine whether a borderline case of a tall man is tall there is no epistemic vantage point that can increase my degree of belief. Schiffer argues that this is a state of epistemic indeterminacy. Nevertheless, provided that expressivists cannot explain standard accounts of uncertainty, it is unclear how they can account for this unique kind.

This section demonstrates that cognitivism has a clear advantage over expressivism in accounting for vagueness. Expressivism does not have enough structure to provide a plausible account of ethical vagueness. This is a serious cost because it demonstrates that there are certain normative judgments that expressivists cannot capture, while cognitivists can.

\section{Deny the Problem}

In responding to this objection, expressivists might simply deny that ethical vagueness exists. If this is right, then they do not have to account for it, thus dissolving the problem of ethical vagueness. There are at least two distinct ways of denying ethical vagueness. Let us call the following version the 'erring on the side of caution' objection. ${ }^{35}$ The driving force of this objection is that claims of the sort ' $P$ and it is vague that $P$ ' cannot be true, or at the very least, claims of this sort are not coherently assertable. With this in mind someone might argue as follows. If it is wrong to do action $A$ in situation $S$, then one should avoid doing $A$ in $S$. Additionally, if it is vague whether it is wrong to do $A$ in $S$, one should err on the side of caution and avoid doing $A$ in $S$. Now it is plausible that if one should avoid doing $A$ in $S$, then $A$ in $S$ is wrong. If this is right, then it follows that if it is vague whether it is wrong to do $A$ in $S$, then it is wrong to do $A$ in $S$. And if claims cannot be of the sort ' $P$ and it is vague that $P$ ', then

\footnotetext{
${ }^{34}$ See Schiffer (2003). See also Wright (2001).

${ }^{35}$ I thank Chad Carmichael for this point.
} 
it is not actually vague if it is wrong to do $A$ in $S$. In other words, in all instances where it seems that it is vague whether it is wrong to do $A$ in $S$, it is simply wrong to do $A$ in $S$.

However, it is questionable whether 'erring on the side of caution' can be applied in all cases involving ethical vagueness. In some circumstances it is not clear what it would mean to err on the side of caution. As I previously discussed some think that a morally relevant factor in determining maternal obligation is the mother's responsibility for creating the situation of fetal dependence. It is plausible that there are borderline causes of responsibility and in these situations it is not at all clear what it would mean to err on the side of caution. For example, if we 'err on the side of caution' and assume that the mother is responsible, and are wrong about this assumption, then this false reasoning might lead us to severely violate her autonomy. But if we 'err on the side of caution' and assume that she is not responsible, and are wrong about this assumption, then one could argue that this could lead to bad consequences as well. The main point is that often times when one confronts ethical vagueness it is not clear what the risk averse action is, and thus it is not helpful to say one should 'err on the side of caution' because it is unclear what that would entail.

Another way one might deny ethical vagueness is by objecting that the sorites construction of 'wrong' is misleading. The sorites construction does not show that 'wrong' is vague, but that some other non-ethical predicate, such as 'few' is vague. And that the vagueness of 'few' is mistakenly transferred to 'wrong', such that we think that 'wrong' is vague. For example, it might be clearly wrong to take more than a few pennies, but it is vague as to what amount of pennies constitutes a 'few'. In other words, all of the problems of 'ethical vagueness' stem from vagueness surrounding terms like 'few' and 'bald', which are not distinctively moral matters.

The problem with this response is that the predicate 'few' is a value laden concept in this particular situation. Consider the following example. Jonathan is baking a cake and his mother Betsy walks over to him and says, "make sure you add a few pinches of salt to the cake'. Later when Betsy takes a bite out of the cake, Jonathan asks, 'Did I add enough salt?' She remarks, 'You added too much'. In this situation, the 'fewness' of the salt is inextricably tied to Betsy's aesthetic taste. That is, there is no way to discuss the 'fewness' of the salt without considering Betsy's aesthetic judgments. When the cake tastes too salty to her, then this means that Jonathan added too much salt. When the cake is not salty enough to her, then this means that Jonathan did not add enough salt. Likewise, when Tom judges that Jessica took more than a few pennies, he is proclaiming that she took more than the amount that it is appropriate to take according to his normative commitments. Hence, judgments about the 'fewness' of the amount of pennies are inextricably linked in this context to judgments about the moral appropriateness of taking said amount of pennies. Therefore, it might be possible to redescribe sorites constructions involving clear ethical predicates (such as 'wrong') in terms of seemingly non-ethical predicates (such as 'few'), but in these situations the seemingly non-ethical predicates are value laden.

\section{Conclusion}

In this paper I developed a novel problem for expressivism - the problem of ethical vagueness. I explained that cognitivists can explain the phenomena of ethical vagueness through uncertainty or indeterminacy. I argued that expressivists cannot account for either uncertainty or indeterminacy and thus do not have a compelling way to explain ethical vagueness. Of course, 
this does not show that expressivism cannot account for vagueness to the extent that there might be other options available which I have not considered here. Nonetheless, the burden is shifted and it is up to expressivists to show how this is possible. Perhaps in attempting to do this an improved version of expressivism will rise forth.

Acknowledgments I received helpful feedback presenting versions of this paper at the University of Missouri in St. Louis Graduate Conference, the Illinois Philosophical Association, the University of Southern CaliforniaUniversity of California, Los Angeles Graduate Conference, and the British Society for Ethical Theory. I thank the following individuals for their help with this paper: Nate Adams, Chad Carmichael, Anna Christensen, Christian Constantinescu, Mike Dacey, Jeff Dauer, Tom Dougherty, Jason Gardner, David Johnson, Sarah Malanowski, Tyler Paytas, Katie Rapier, Felipe Romero, Gillian Russell, Roy Sorensen, Bryan Stagner, Christopher Heath (Kit) Wellman, Isaac Wiegman, Eric Wiland, Gary Williams. I would also like to extend a very special thank you to Charlie Kurth, who has read countless drafts and encouraged me to pursue this project.

\section{References}

Aristotle (2002). Nicomachean ethics. Rowe and Broadie (trans and com) Oxford University Press Ayer AJ (1936) Intention. Blackwell Press, Oxford

Blackburn S (1993) Spreading the word, essays in quasi-realism. Oxford University Press, New York

Blackburn S (1998) Ruling passions. Oxford University Press, New York

Bykvist K, Olson J (2009) Expressivism and moral certitude. Philos Q 59:202-215

Constantinescu, C. (forthcoming). Moral vagueness: a dilemma for non-naturalism. Oxf Stud in Metaethics.

D'Arms J, Jacobson D (2000) Sentiment and value. Ethics 110:722-748

Dreier J (2006) Negation for expressivists: a collection of problems with a suggestion for their solution. Oxf Stud in Metaethics 1:217-233

Fine K (1975) Vagueness, truth and logic. Synthese 54:235-259

Gibbard A (1990) Wise, choices, apt feelings. Harvard University Press, Cambridge, Mass

Gibbard A (2003) Thinking how to live. Harvard University Press, Cambridge, Mass

Hare R M (1952). The language of morals. Oxford University Press

Hyde D (2008) Vagueness, logic and ontology. Ashgate Publishing, Aldershot

Lenman J. (2003). Non-cognitivism and the dimensions of evaluative judgment. In Dreier J \& Estlund D (eds) Brown Electronic Article Review Service. www.brown.edu/departments/philosophy/bears/homepage.html.

Lewis C (1982) Logic for equivocators Noûs 16:431-441

McDowell J (1997a) Values and secondary qualities and projection. In: Darwall S, Gibbard A, Railton P (eds) Moral discourse and practice. Oxford University Press, Oxford, pp 201-214

McDowell J (1997b) Projection and truth in ethics. In: Darwall S, Gibbard A, Railton P (eds) Moral discourse and practice. Oxford University Press, Oxford, pp 215-226

Railton P (1992) Pluralism, determinacy, and dilemma. Ethics 102:720-742

Ridge M (2007) Ecumenical expressivism: the best of both worlds?'. Oxfor Stud in Metaethics 2:51-76

Rosen G, Smith NJJ (2004) Worldly indeterminacy: a rough guide. Aust J Philos 82:198-98

Sainsbury R M (1997). Concepts without boundaries. In: Keefe R \& Smith P (eds) Vagueness: a reader. MIT Press: 251-264

Schiffer S (2003) The things we mean. Oxford University Press, Oxford

Schiffer S. (2010). Vague properties. In Dietz and Moruzzi (eds) Cuts and clouds: essays on the nature and logic of vagueness. Oxford University Press, pg. 109-130

Schroeder M (2010) How to be an expressivist about truth. In: Pedersen NJ, Wright C (eds) New waves in truth. Palgrave MacMillan, New York, pp 282-298

Sepielli A (2012) Normative uncertainty for non-cognitivivsts. Philos Stud 160:191-207

Shafer-Landau R (1994) Ethical disagreement, ethical objectivism, and moral indeterminacy. Philos and Phenomenol Res 54:331-344

Shafer-Landau R (1995) Vagueness, borderline cases and realism. American Philos Q 32:83-96

Shroeder M (2008) Being for: evaluating the semantic program for expressivism. New York, Oxford

Smith M (2002) Evaluation, uncertainty, and motivation. Ethical Theory and Moral Practice 5:305-320

Sorensen R (1988) Blindspots. Clarendon Press, Oxford

Sorensen R (1990) Vagueness implies cognitivism. Am Philos Q 27:1-14

Sorensen R (1991) Moral dilemmas, thought experiments, and conflict vagueness. Philos Stud 63:291-308 
Tye M (1989) Supervaluationism and the law of excluded middle. Analysis 49:141-143

Unwin N (1990) Quasi-realism, negation, and the frege-geach problem. Philos Q 49:337-352

Wiggins D (1997) A sensible subjectivism? In: Darwall S, Gibbard A, Railton P (eds) Moral discourse and practice. Oxford University Press, Oxford, pp 227-246

Williamson T (1994) Vagueness. Routledge, London

Wright C (2001) On being in a quandary. Mind 110:45-98 